information given, like many of the recordings, is right up to date and the jackets carry full annotations, together with an introduction by $\mathrm{Mr}$ Simms.

Bruce Campbell

\section{NO BONES ABOUT POLYMERS}

Polysaccharide-Protein Complexes in Invertebrates By S. Hunt. Pp. v+329. (Academic: London and New York, March 1970.) 100s.

ThIs is a careful compilation of facts in an area where facts are short and the connoisseur of polysaccharide structure will find it fascinating. Molecules are portrayed which have the interest of the flora and fauna of a newly discovered Australasia-so strangely the same, yet so strangely different, compared with other continents of the kingdoms of life.

It is very much the book of a biologist, and a chemist's susceptibilities are often offended. He is left to make what he can, without explanation, of materials which are "PAS positive" (p. 35), or emerge from "Sevag treatment" (p. 37) or "treatment with Lloyd's reagent" (p. 21), and so on throughout the book. Perhaps he misses the point by pausing to ask for a literal translation of each ritual phrase ? There is excessive discussion of technique, and minor experimental details are recited as if they came down from Sinai on tablets of stone rather than being, so often, arbitrary. It is difficult to remain calm when glycosaminoglycan types are discussed as if each structure is as well defined as benzoic acid or methane, and when homage is paid to my own bête noir, the "calcium bridge" (p. 107). Alternative molecular structures are earnestly presented when there is little foundation for any (for example, pp. 107-108). The speculation about heteropolysaccharide biosynthesis, in a key part of the book (p. 290), is not informed by the knowledge since 1965 of such systems in bacteria. Indeed, the derivatized chitin of bacterial cell walls is not mentioned, even though it might be a "missing link" that the author seeks in molecular evolution.

Compensations do, however, follow from this biological perspective. Chapter sixteen is an exciting discussion of the evolution of polysaccharides, and there are profound thoughts about polysaccharide function throughout the book. These provide a refreshing change from the lame teleological arguments that are furtively aired by chemists and by chemical and physical biochemists. This book ought to be widely available, and deserves to be much read and discussed by those working in related research areas.

D. A. REES

\section{IDENTIFYING BLOODSTAINS}

La Recherche des Antigènes $\mathrm{Gm}$ dans les Taches de Sang pour leur Identification Biologique et Médicolégale

By Robert Görtz. (Centre National de la Recherche Scientifique. Monographics du Centre d'Hémotypologie, CHU du Toulouse.) Pp. 131. (Hermann: Paris, 1970.) n.p.

THE contents of this monograph are not confined to the subject indicated by the title. The historical and theoretical aspects of the $\mathrm{Gm}$ system are considered at some length but no significant information emerges which is not available elsewhere. The identification of other factors in bloodstains is also discussed, but, apart from somewhat cursory mention of absorption-elution, mixed agglutination and fluorescent antibody techniques, this section is devoted almost entirely to the use of the classical absorption-inhibition method for the detection of red cell antigens and is therefore far from comprehensive. There is also a brief chapter on the use of Gm typing for paternity testing.
In dealing with the detection of Gm factors in dried bloodstains an account of previous work on the subject is given. Attention is drawn to the fact that, because of the large number of antigens in the system, it would be possible to obtain a more precise identification of stains than by the red cell factors providing the quantity of stain was sufficient. (This is obviously assuming availability of the full range of suitable Gm typing sera.) The method for typing fluid serum samples is given, together with the adaptations for working with dried bloodstains. These consist of substituting pieces of bloodstained material, powdered blood or saline extracts of stains in plsice of the serum samples.

Various factors are considered which could influence the results obtained from stains. These include the type of serum, time and temperature conditions for absorption, the quantity and the age of bloodstains. Most of the work was carried out in respect of antigens $\mathrm{Gm}(1), \mathrm{Gm}(2)$ and $\mathrm{Gm}(5)$. Original work is also reported on the identification of $\mathrm{Gm}(3), \mathrm{Gm}(6)$ and $\mathrm{Gm}(10)$. A remarkably high standard of reliability is elaimed even with staine which were several years old. Very detailed results are given and there is an abundance of tables, graphs and histograms.

A comparison is also made of serum samples and bloodstains obtained from newborn infants and their mothers. It is shown that, at birth, the baby has an identical Gm phenotype with that of its mother.

Margaret Pereira

\section{SULPHUR BIOCHEMISTRY}

The Biochemistry of Inorganic Compounds of Sulphur By A. B. Roy and P. A. Trudinger. Pp. xv +400 . (Cambridge University: London, June 1970.) 120s; $\$ 18.50$.

ThE complexity of the field of sulphur biochemistry reflects the reactivity of the element itself and anybody with even the scantiest knowledge of the subject will readily appreciate that the authors of this book were faced with a formidable task. For the first time an attempt has been made to bring together in a single volume knowledge from various branches of the subject; knowledge which would be of value both to the general reader and to the specialist who is seeking a work of reference. The authors have attempted to dissociate the subject matter from the more familiar aspects of organic sulphur biochemistry. The distinction, however, between inorganic and organic compounds of sulphur is rather tenuously defined and to some readers the title of tho book may seem to be misleading.

In thirteen chapters the authors cover the chemistry, enzymology, metabolism and biological significance of a wide range of compounds including simple molecules such as sulphide, sulphite, sulphate, thiosulphate and dithionate, and relatively complex compounds such as mustard oil glycosides, sulphate and thiosulphate esters, sulphamates, sulphatophosphates, sulphonic acids and steroid sulphatides. In the earlier chemical chapters attempts are made to relate structure with chemical reactivity and methods for the preparation and analysis of some of the more important compounds are deseribed. In this last respect the book tends to fall between two stools because the treatment is certainly not sufficiently comprehensive for the specialist and may be considered superfluous by the ordinary reader.

A large section of the book is devoted to the biochemistry of the sulphate ion and deals with the enzymatic activation of sulphate, its transfer by way of sulphotransferase enzymes, to various types of acceptor to yield sulphate esters, and the hydrolysis of these ester's by sulphatases. Much of the material presented has previously been reviewed by various workers, but the 